\title{
Aplicabilidade dos qualificadores da Classificação Internacional de Funcionalidade, Incapacidade e Saúde (CIF) em pacientes neurológicos adultos em um centro de reabilitação em São Paulo, Brasil
}

\section{Feasibility of the International Classification of Functioning, Disability and Health (ICF) qualifiers in adult neurological patients on a rehabilitation center in Sao Paulo, Brazil}

Juliana Leme Gomes ${ }^{1}$, (D) Uleida de Brito Lima Lopes ${ }^{1}$, Simone Ferreira de Freitas ${ }^{1}$, Luana Talita Diniz Ferreira $^{1}$, Clarissa Barros de Oliveira ${ }^{1}$

\section{RESUMO}

A Classificação Internacional de Funcionalidade, Incapacidade e Saúde (CIF) vem sendo utilizada na Associação de Assistência à Criança com Deficiência (AACD) desde 2011 no setor de Fisioterapia Adulto. Esta Classificação, desde então, serve como base para nortear os objetivos funcionais traçados, para melhorar a comunicação entre os setores multiprofissionais e para indicar qualidade assistencial para fins de auditoria de serviço institucional. A experiência foi válida para a instituição e bem aceita pelos seus colaboradores, e seu uso pôde ser expandido. A Organização Mundial da Saúde (OMS) sugere que o uso dos códigos da CIF não está completo sem a utilização dos seus qualificadores. Dessa forma o presente trabalho tem como objetivo descrever a implantação da CIF e seus qualificadores no setor de fisioterapia de adultos da instituição. $O$ instrumento adaptado para uso neste serviço permite avaliar o paciente na sua admissão e acompanhar sua evolução ao longo do seu processo de reabilitação, de forma a ser utilizado como indicador de evolução setorial. Será relatado nesse trabalho o processo que foi realizado: a implantação da classificação, o estudo de aprofundamento na qualificação preconizada; desenvolvimento de um instrumento adequado para a prática clínica do serviço; treinamento dos profissionais e projeto piloto; além de reportar dados iniciais na forma de indicadores de evolução.

Palavras-chave: Classificação Internacional de Funcionalidade, Incapacidade e Saúde, Pessoas com Deficiência, Manifestações Neurológicas, Centros de Reabilitação, Fisioterapia

${ }^{1}$ Associação de Assistência à Criança com Deficiência - AACD

\section{Correspondência \\ Juliana Leme Gomes \\ E-mail: jugomes@aacd.org.br}

Submetido: 13 Setembro 2019.

Aceito: 14 Novembro 2019.

Como Citar

Gomes JL, Lopes UBL, Freitas SF, Ferreira LTD, Oliveira CB. Aplicabilidade dos qualificadores da Classificação Internacional de Funcionalidade, Incapacidade e Saúde (CIF) em pacientes neurológicos adultos em um centro de reabilitação em São Paulo, Brasil. Acta Fisiatr. 2019;26(1):25-36.

DOI: 10.11606/issn.2317-0190.v26i1a163787

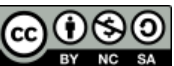

\section{ABSTRACT}

The International Classification of Functioning, Disability and Health (ICF) has been used in the Association of Assistance for Disabled Children (AACD) since 2011 in the Adult Physiotherapy division. Since then, the Classification serves as foundation for guiding the functional objectives set, improving communication between multiprofissional divisions and indicating quality of care for institutional audit service purposes. The experience was valid for the institution and well accepted by its employees, and the use was expanded. The World Health Organization (WHO) suggests that the ICF codes' use is not complete without their qualifiers. Therefore, this paper aims to describe the implementation of ICF and its qualifiers in the adult physiotherapy division of the institution. The instrument, which was adapted for use in our servisse, allows the patients to be evaluated on their admission and to monitor the evolution throughout their rehabilitation process, in order to be used as an evolution indicator. This study will report the process we performed: the implementation of the Classification; the study to deepen knowledge on the recommended qualification; development of an appropriate instrument to be used for clinical practice of this service; staff training and pilot application; and, in addition, to report initial data as progress indicators.

Keywords: International Classification of Functioning, Disability and Health, Disabled Persons, Neurologic Manifestations, Rehabilitation Centers, Physical Therapy Specialty 


\section{INTRODUÇÃO}

A Classificação Internacional de Funcionalidade, Incapacidade e Saúde (CIF) pertence à Família das Classificações Internacionais da Organização Mundial da Saúde (OMS). Ela se propõe a descrever os componentes de saúde do indivíduo, levando em conta o contexto biopsicossocial em que ele está inserido. ${ }^{1}$ No contexto reabilitacional, o uso da CIF permite a visualização da funcionalidade do indivíduo, as dificuldades e potencialidades inerentes a sua condição de saúde, ambiente e dinâmica social que pontuam necessidades de intervenção e demandas a serem avaliadas. ${ }^{2}$

O uso da classificação nos serviços de fisioterapia é preconizado pela Confederação Mundial de Fisioterapia $^{3}$ e pela Associação Americana de Fisioterapia ${ }^{4}$ e é constantemente incentivada, sendo crescente o número de trabalhos propondo maneiras de utilizá-la no Brasil $^{5}$ e no mundo. ${ }^{6}$

Segundo a CIF, a funcionalidade de um indivíduo pode ser registrada através de códigos alfanuméricos. O uso de qualificadores é recomendado para especificar a extensão da funcionalidade ou incapacidade na categoria selecionada. ${ }^{1}$

$\mathrm{O}$ uso dos qualificadores é escasso na literatura. Ao ser comparado com outros instrumentos de avaliação validados, mostra-se eficaz e demonstra grande potencial para ser usado como instrumento para medir e coletar dados funcionais do paciente. ${ }^{7}$ Entretanto, estudos apontam que pode ter seu uso melhorado para a prática clínica. ${ }^{7-9}$

A Associação de Assistência à Criança com Deficiência (AACD), conhecendo a tendência mundial do uso desta Classificação e percebendo a riqueza de descrição e sua importância optou por implantar a CIF no processo de reabilitação do paciente na instituição.

\section{OBJETIVO}

0 presente trabalho tem como objetivo descrever o desenvolvimento de um instrumento de avaliação e indicador de evolução de pacientes atendidos no setor de fisioterapia adulto da $A A C D$, além de descrever os resultados iniciais obtidos.

\section{MÉTODO}

\section{Processo de criação do instrumento}

A AACD desde 2010 mostrava interesse pelo uso da CIF na prática clínica, visto a visibilidade e importância que a classificação vinha ganhando na área da saúde. 3,4 No ano de 2011 foi implantado o uso dos códigos da CIF na rotina clínica do setor de Fisioterapia Adulto.

Para tanto foram compilados os objetivos funcionais mais utilizados dentro do setor pelos terapeutas e criada uma lista relacionando-os aos códigos da CIF equivalentes (Quadro 1). Esse processo permitiu os terapeutas que se familiarizassem com a Classificação e incorporassem seus códigos a sua prática clínica.

Os indicadores de qualidade do setor, nesta fase, baseavam-se na frequência com que cada objetivo funcional era trabalhado. A evolução do paciente era avaliada de forma categorizada e subjetiva: objetivo atingido de forma total, parcial ou não atingido, sem uso de qualificadores, ou seja, cada terapeuta indicava a evolução do paciente baseando-se em sua experiência clínica e observação no momento da reavaliação.

O modelo inicial foi utilizado de 2011 a 2016. Após este período, a ferramenta foi novamente adaptada a realidade do serviço. Aos códigos já utilizados foram acrescentados os qualificadores propostos pela CIF, visando acompanhar a evolução dos nossos pacientes de forma objetiva ao longo do processo de reabilitação.

\section{A criação de um instrumento baseado nos qualificadores da CIF}

O modelo inicial foi utilizado de 2011 a 2016. Nesse ano um grupo de fisioterapeutas desenvolveu um instrumento acrescentado aos códigos já utilizados os qualificadores propostos pela CIF, propondo seu uso na prática clínica de forma simples e prática. Os principais objetivos nesta etapa foram:

1. Quantificar a evolução do paciente dentro dos objetivos funcionais traçados de forma individualizada;

2. Tornar mais quantitativa a evolução funcional do paciente;

3. Gerar indicadores mais precisos;

4. Trazer para a equipe uma linguagem única, ou seja, trabalhar de forma padronizada dentro do mesmo serviço.

Os qualificadores da CIF são a continuidade dos códigos alfanuméricos que especificam a extensão ou magnitude do comprometimento no componente de saúde. ${ }^{1}$ Quando relacionado a um código de função do corpo indica a magnitude de uma deficiência e quando relacionado a um código de atividades ou participação indica a sua capacidade e/ou desempenho naquela tarefa em questão.

A CIF sugere que todos os códigos devem conter pelo menos um qualificador para fornecer a real imagem da saúde do indivíduo. Eles são quantificados através de uma escala genérica apresentada (Quadro 2) e representados pelos números que vem após o ponto.

Os qualificadores foram utilizados para indicar o grau de dificuldade dos pacientes em realizar as funções determinadas como objetivos de reabilitação: os pacientes eram avaliados pelo seu terapeuta através dos qualificadores para indicar seu grau de funcionalidade no objetivo escolhido para o período (representado por um código da CIF) e, após três meses (tempo determinado institucionalmente para o treino da função escolhida) o código era reavaliado pelo mesmo terapeuta para verificar se houve evolução do quadro clínico dentro deste período.

A utilização dos qualificadores genéricos já possibilitava uma avaliação quantitativa da evolução do paciente, mas apresenta uma característica de subjetividade que inviabilizava seu uso por profissionais distintos. Em busca de reduzir a subjetividade do processo e visando padronizar a linguagem e os testes utilizados, optou-se por descrever para cada código da CIF o perfil funcional esperado para cada qualificador.

A evolução desse paciente seria obtida apenas se na reavaliação houvesse mudança positiva no qualificador, ou seja, melhora no desempenho funcional na tarefa de acordo com o teste utilizado. 0 resumo do formato da aplicação do instrumento pode ser observado (Figura 1).

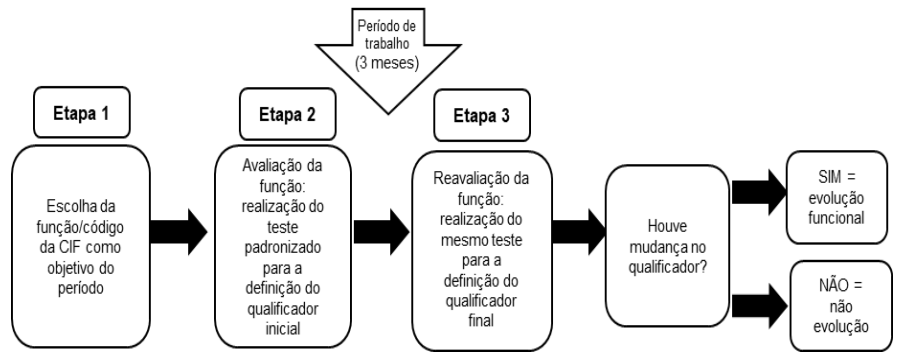

Figura 1. Fluxograma de aplicação do instrumento durante a rotina de atendimento no setor de fisioterapia adulto

Buscamos testes validados na literatura para a nos basear ao realizar a adaptação dos qualificadores. A lista de códigos da CIF utilizados no setor (criada em 2011) serviu como referência dos objetivos funcionais que seriam utilizados. Para cada código/objetivo funcional um teste foi escolhido.

Inicialmente instrumentos já calibrados para o uso dos qualificadores (processo de linkage, relatado na literatura) ${ }^{10,11}$ foram utilizados. Entretanto, nem todos os objetivos funcionais usados no departamento de fisioterapia adulto estavam inclusos em testes calibrados.

Por esta razão, optamos por utilizar outras escalas validadas que apresentavam objetivos semelhantes ou, determinar os perfis funcionais baseando-nos na experiência dos profissionais da instituição. 
Quadro 1. Lista de objetivos da fisioterapia utilizada em 2011 no setor de Fisioterapia Adulto

\section{1) d450 - Andar/ d460 - Deslocar-se}

\section{LISTA DE OBJETIVOS DA FISIOTERAPIA - INDICADOR DE EVOLUÇÃO BASEADO NA CIF}

d4502 - Andar sobre superfícies diferentes

d4503 - Andar desviando-se de obstáculos

d4600 - Deslocar-se dentro de casa

d4602 - Deslocar-se fora de casa e de outros prédios

d465 - Deslocar-se utilizando algum tipo de equipamento

\section{2) d420 - Transferências}

d4200 - Transferir-se enquanto sentado

d4208 - Transferir a própria posição, outra especificada

3) d410 - Trocas posturais

d4100 - Deitar e/ou Rolar

d4103 - Sentar-se

d4104 - Levantar-se

d4106 - Mudar o centro de gravidade do corpo

4) d415 - Manutenção da postura

d4153 - Permanecer sentado

d4154 - Permanecer em pé

5) b755 - Equilíbrio

b2351 - Função vestibular de equilíbrio

d4106 - Mudar o centro de gravidade do corpo

6) d179 - Orientações

d410 - Mudar a posição básica do corpo

d415 - Manter a posição do corpo

d420 - Transferir a própria posição

b710 - Funções relacionadas à mobilidade das articulações

b730 - Funções relacionadas à força muscular

b798 - Funções neuromusculoesqueléticas e relacionadas com o movimento, outras especificadas (neuroma, sensação ou dor fantasma, conificação de coto)

7) PPP - Preparação Pré-Protética

b710 - Funções relacionadas à mobilidade das articulações

b730 - Funções relacionadas à força muscular

b740 - Funções relacionadas à resistência muscular

b798 - Funções neuromusculoesqueléticas e relacionadas com o movimento, outras especificadas (neuroma, sensação ou dor fantasma, conificação de coto)

8) CF/FR - Condicionamento/ Funções respiratórias

b420 - Funções da pressão sanguínea

b440 - Funções respiratórias (frequência respiratória, ritmo respiratório, funções respiratórias especificadas)

b455 - Funções de tolerância a exercícios (resistência física geral, capacidade aeróbia, fadiga, tolerância a exercícios)

9) PO - Pós-operatório

b280 - Sensação de Dor

b4352 - Funções dos vasos linfáticos (edema)

b820 - Funções reparadoras da pele (cicatrização, aderências)

b710 - Funções relacionadas à mobilidade das articulações

b730 - Funções relacionadas à força muscular

b735 - Funções relacionadas ao tônus muscular

b740 - Funções relacionadas à resistência muscular

10) AVDs - Atividades de vida diária

d530 - Cuidados relacionados ao processo de excreção (usar o banheiro)

d540 - Vestir-se

d550 - Comer

Quadro 2. Escala de qualificadores genéricos da CIF

\begin{tabular}{|c|c|c|}
\hline xxx.0 NÃO há problema & (nenhum, ausente, insignificante) & $0-4 \%$ \\
\hline xxx.1 Problema LIGEIRO & (leve, pequeno, ...) & $5-24 \%$ \\
\hline xxx.2 Problema MODERADO & (médio, regular, ...) & $25-49 \%$ \\
\hline xxx.3 Problema GRAVE & (grande, extremo, ...) & $50-95 \%$ \\
\hline xxx.4 Problema COMPLETO & (total, ...) & $96-100 \%$ \\
\hline \multicolumn{3}{|l|}{ xxx.8 não especificado } \\
\hline
\end{tabular}

"xxx" representa o código em questão e os qualificadores são os números situados após o ponto. Caso o código tenha mais de um qualificador a sua posição também determina o que está sendo demonstrado em relação ao componente de saúde avaliado 
Os testes selecionados foram: Medida de Independência Funcional - MIF, ${ }^{12}$ Berg Balance Scale, ${ }^{13}$ Timed Up and Go test ${ }^{14}$ - esses calibrados pelo processo de linkage, ${ }^{15,16}$ além dos BESTest, ${ }^{17}$ MAS, ${ }^{18}$ Teste de Caminhada de 6 minutos, ${ }^{19}$ DGI, ${ }^{20}$ das escalas de avaliação segmentar Escala Visual Analógica ${ }^{21}$ para dor, Teste Muscular Manual de Kendall ${ }^{22}$ para força, Escala de Ashworth Modificada ${ }^{23}$ para espasticidade e a goniometria ${ }^{24}$ para amplitude de movimento) já relacionadas com a ClF, publicadas por Coelho JN na sua dissertação de mestrado. ${ }^{25}$ Os testes que não passaram pelo processo de calibragem foram adaptados para as classes de percentagem sugeridas pelo modelo genérico de qualificadores da CIF.

Ao realizar as adaptações nos atentamos a descrição do teste original, as sugestões de perfis funcionais apresentados por eles, mas principalmente a descrição de porcentagem e nível de independência sugeridos pela CIF na escala genérica de qualificadores.

Considerando os códigos relativos ao componente de Atividade e Participação, a definição dos cinco itens dos qualificadores seguiu regras em relação ao nível de independência do paciente (quando o teste tinha o objetivo de verificar maior independência do paciente após o período de trabalho) e grau de dificuldade em realizar tarefas complexas (quando o teste tinha o objetivo de verificar melhor execução de uma tarefa que o paciente já realiza sozinho) que estão dispostas (Quadro 3).

Quadro 3. Relação entre os qualificadores propostos pela OMS e regras em relação ao nível de independência dos pacientes e grau de dificuldade em realizar tarefas complexas para adaptação do instrumento criado

\begin{tabular}{|c|c|c|c|}
\hline Qualificadores & $\begin{array}{l}\text { Perfis funcionais de } \\
\text { acordo com a escala } \\
\text { genérica proposta } \\
\text { pela OMS }\end{array}$ & $\begin{array}{l}\text { Perfis funcionais } \\
\text { adaptados de acordo } \\
\text { com o nível de } \\
\text { independência }\end{array}$ & $\begin{array}{l}\text { Perfis funcionais } \\
\text { adaptados de } \\
\text { acordo com o grau } \\
\text { de dificuldade }\end{array}$ \\
\hline 0 & $\begin{array}{l}\text { Não há problema (0 } \\
\text { a } 4 \%)\end{array}$ & $\begin{array}{l}\text { total independência } \\
\text { do paciente }\end{array}$ & $\begin{array}{l}\text { independência em } \\
\text { tarefas mais } \\
\text { complexas sem } \\
\text { dificuldade }\end{array}$ \\
\hline 1 & $\begin{array}{l}\text { Problema ligeiro (5 a } \\
24 \% \text { ) }\end{array}$ & $\begin{array}{l}\text { dependência leve, } \\
\text { necessidade de } \\
\text { supervisão }\end{array}$ & $\begin{array}{l}\text { independência em } \\
\text { tarefas complexas } \\
\text { com algum nível de } \\
\text { dificuldade }\end{array}$ \\
\hline 2 & $\begin{array}{l}\text { Problema moderado } \\
\text { ( } 25 \text { a } 49 \%)\end{array}$ & $\begin{array}{l}\text { necessidade de auxílio } \\
\text { de leve a moderado } \\
\text { de terceiros }\end{array}$ & $\begin{array}{l}\text { Independência em } \\
\text { tarefas simples, ou } \\
\text { etapas da tarefa } \\
\text { complexa sem } \\
\text { dificuldade }\end{array}$ \\
\hline 3 & $\begin{array}{l}\text { Problema grave (50 a } \\
95 \% \text { ) }\end{array}$ & $\begin{array}{l}\text { auxílio grave de } \\
\text { terceiros }\end{array}$ & $\begin{array}{l}\text { independência em } \\
\text { tarefas simples ou } \\
\text { em etapas da } \\
\text { tarefa complexa } \\
\text { com dificuldade }\end{array}$ \\
\hline 4 & $\begin{array}{l}\text { Problema completo } \\
\text { (96 a 100\%) }\end{array}$ & $\begin{array}{l}\text { ou auxílio total de } \\
\text { terceiros }\end{array}$ & $\begin{array}{l}\text { não consegue } \\
\text { completar a tarefa } \\
\text { simples ou etapas } \\
\text { da tarefa complexa } \\
\text { de forma } \\
\text { independente }\end{array}$ \\
\hline
\end{tabular}

\section{A apresentação do instrumento e implantação}

O instrumento foi apresentado para a equipe em março de 2017. Em seguida foi iniciado um projeto piloto (Número CAAE: 01796918.1.0000.0085), de aplicação para adaptação ao instrumento e forma de transcrição para o prontuário. Ele foi disposto em três pastas físicas que continham os testes, um índice, um guia prático de como aplicá-lo (Quadro 4) e folhas pautadas no final para que os terapeutas descrevessem quaisquer dificuldades ou sugestões. Sugestões da equipe foram incentivadas buscando melhorias no instrumento e no processo.
Quadro 4. Folha de rosto utilizada inicialmente para facilitar entendimento e aplicação dos qualificadores da CIF na prática clínica do setor de fisioterapia adulto

\section{LISTA DE OBJETIVOS FUNCIONAIS E QUALIFICADORES DA CIF}

QUALIFICADORES GENÉRICOS

Xxx.0 NÃO há problema (nenhum, ausente, insignificante) 0-4\%

xxx.1 Problema LIGEIRO (leve, pequeno, ...) 5-24\%

xxx.2 Problema MODERADO (médio, regular, ...) 25-49\%

xxx.3 Problema GRAVE (grande, extremo, ...) 50-95\%

xxx.4 Problema COMPLETO (total, ...) 96-100\%

$x x x .8$ não especificado

xxx.9 não aplicável

\section{RELATÓRIO DE EVOLUÇÃO:}

Objetivo(s)principais do período:

O que foi trabalhado, escolhido no período anterior com qualificador (como o paciente estava antes do objetivo ser trabalhado).

Exemplo: d465.4 Desloca-se com andador em ambiente domiciliar Qualificação atual/Ação:

Reavaliar da mesma maneira a classificar como novo qualificador caso tenha mudado, se não mudou justificar e descrever a ação (em caso de objetivos não atingidos ou parcialmente atingidos)

Exemplo:

$(*)$ Atingido

d465.2 Desloca-se com bengala quatro pontos em ambiente domiciliar Justificativa:

1) Paciente atingiu objetivo e seu prognostico é para marcha com bengala 4 pontos no momento, trocar objetivo e realizar teste pertinente ao novo objetivo escolhido.

2) Paciente atingiu o objetivo, porém ainda pode melhorar mais dentro desse mesmo objetivo, por exemplo, tem condições de mudar a aditamento, manter o objetivo com o qualificador atual (d465.2)

3) Paciente atingiu parcialmente ou não atingiu o objetivo, justificar falta da evolução e decidir se mantem o mesmo objetivo (d465.2) ou ele será trocado.

A aplicação piloto ocorreu com pacientes com Lesões Encefálicas Adquiridas (LEA) e durou 3 meses. Foram incluídos todos os pacientes da clínica de LEA (pacientes que apresentavam comprometimento sensório-cognitivo-motor devido a uma lesão na estrutura do encéfalo, por exemplo: acidente vascular encefálico, traumatismo crânio encefálico, encefalites, doença de Parkinson, entre outros) atendidos no setor que tiveram seus relatórios realizados no período. Em casos de prejuízo cognitivo que impossibilitasse a resposta a itens de relato, o acompanhante que estava presente na rotina diária do paciente respondia.

O grupo responsável pela criação e implantação do instrumento acompanhou pelos prontuários eletrônicos a aplicação e o registro do novo modelo a fim de verificar adesão e minimizar erros durante o processo.

No primeiro semestre de 2018 iniciamos a análise dos dados iniciais considerando os pacientes com LEA. Foram 27 terapeutas, 386 relatórios tabulados. Os resultados para as variáveis de evolução (sim ou não), número de relatórios perdidos (por dados incompletos ou erros), motivos de não evolução e categoria funcional foram analisados em forma de frequência absoluta e relativa considerando os períodos mensal e semestral.

Não houve análise de comparação entre os dados, pois foram utilizados para ilustrar a aplicação. Eventuais erros de aplicação também foram tabulados. As maiores dificuldades/falhas, destacavam os pontos a serem reforçados na reunião semanal de equipe para garantir melhor eficácia na aplicação do instrumento. Por se tratar de um estudo piloto a equipe responsável estava à disposição para dúvidas durante a aplicação. 


\section{RESULTADOS}

O instrumento final contou com 35 códigos alocados em 9 categorias funcionais e pode ser encontrado no Anexo 1.

Nos três primeiros meses de aplicação do piloto houve dificuldade de entendimento de alguns terapeutas sobre a proposta de avaliação pelos qualificadores. Foram detectados erros na transposição dos códigos para o prontuário, e em alguns casos, a não utilização do qualificador (não ficou claro se por falta de entendimento do uso ou de adesão). As demandas de melhorias por parte dos terapeutas foram de ajustes em relação: a linguagem, a falta de sensibilidade dos itens à evolução dos pacientes ou a não realização dos testes devido a rotina do setor.

Os erros foram solucionados após novo treinamento, que contou com exemplos práticos. Casos isolados eram tratados diretamente com os terapeutas. Foram realizados ciclos de melhoria do instrumento baseados nas demandas levantadas pela equipe. Depois de devidos treinamentos e ajustes no instrumento a resposta geral de aceitação da nova proposta foi satisfatória e seu uso continuado.

\section{Dados iniciais obtidos}

Em relação aos dados tabulados dos meses de janeiro a junho de 2018: dos 386 relatórios avaliados, foram utilizados os qualificadores em 372. Observamos 14 casos em que os qualificadores não foram contabilizados pois os dados não estavam claros no prontuário, totalizando perda de $3,62 \%$ dos casos totais.

Do total, 296 indivíduos avaliados melhoraram o seu qualificador no período. A não evolução ocorreu em $20,43 \%$ dos pacientes. Esses resultados podem ser visualizados (Tabela 1 ) que demonstra também as porcentagens analisadas em cada mês do semestre.

$\mathrm{Na}$ última linha podemos observar o número de relatórios perdidos por mês devido a erros ao longo do processo e sua porcentagem em relação ao total de relatórios. Dos 76 pacientes que não apresentaram evolução, as justificativas foram problemas com o qualificador em $19,73 \%$ dos casos.

As categorias funcionais mais trabalhadas com os pacientes dentro do semestre foram ilustradas (Tabela 2). Treino de atividades relacionadas ao deslocamento ocorreu com maior frequência $(n=146)$, seguido de exercícios de manutenção de alguma postura funcional (como por exemplo ortostatismo ou sedestação).

\section{Desafios encontrados / lições aprendidas}

O maior desafio encontrado foi a adaptação de testes para cada função: eles deveriam ser viáveis para aplicação na prática clínica e sensíveis a evolução dos nossos pacientes. Outro desafio foi a necessidade de buscar escalas que avaliassem um aprimoramento qualitativo na função. Como avaliar a tarefa que o paciente já executa, mas espera-se que ele realize de forma mais eficaz ou com menor dificuldade?

Um exemplo foi a avaliação da qualidade na marcha. Existem testes que avaliam a velocidade da marcha, se ela é funcional em ambientes controlados ou comunitários, porém não se encontra na literatura um teste prático que descreva as compensações realizadas ou o alinhamento das articulações durante a tarefa. Por esta razão, no instrumento da AACD optou-se por listar itens importantes a serem avaliados durante a marcha do paciente, e descrevê-los a partir dos qualificadores genéricos.

Uma grande dificuldade foi delimitar os perfis dos qualificadores, sendo estes somente cinco dentro de uma diversidade imensa de pacientes e comportamentos funcionais. Dentre diversas estratégias, aceitamos que alguns códigos deveriam ser mais abrangentes e buscamos outros códigos para definir particularidades a serem trabalhadas dentro daqueles mais amplos. O terapeuta podia definir se utilizaria um código mais abrangente ou se o paciente apresentava
Tabela 1. Distribuição mensal de evoluções (SIM) e não evoluções (NÃO) obtidas ao longo do primeiro semestre de 2018 em números absolutos e porcentagens

\begin{tabular}{lccccccc}
\hline & JAN & FEV & MAR & ABR & MAI & JUN & TOTAL \\
\hline SIM (\%) & 58 & 45 & 57 & 47 & 48 & 41 & 296 \\
& $(0,77)$ & $(0,77)$ & $(0,81)$ & $(0,83)$ & $(0,77)$ & $(0,80)$ & $(79,56)$ \\
NÃO (\%) & 17 & 13 & 13 & 9 & 14 & 10 & 76 \\
PERDIDOS & $(0,22)$ & $(0,22)$ & $(0,18)$ & $(0,16)$ & $(0,22)$ & $(0,19)$ & $(20,43)$ \\
(\% relação & 3 & 4 & 2 & 1 & 3 & 1 & 14 \\
ao total) & $(3,84)$ & $(6,45)$ & $(2,77)$ & $(1,75)$ & $(4,61)$ & $(1,92)$ & $(3,62)$ \\
TOTAL & 78 & 62 & 72 & 57 & 65 & 52 & 386 \\
\hline
\end{tabular}

Tabela 2. Distribuição mensal de categorias funcionais utilizadas ao longo do primeiro semestre de 2018 em números absolutos

\begin{tabular}{lccccccc}
\hline \multicolumn{1}{c}{$\begin{array}{c}\text { CATEGORIAS } \\
\text { FUNCIONAIS }\end{array}$} & JAN & FEV & MAR & ABR & MAI & JUN & TOTAL \\
\hline Andar/Deslocar & 30 & 28 & 39 & 22 & 35 & 22 & 176 \\
$\begin{array}{l}\text { Atividades Funcionais } \\
\text { Condicionamento/ }\end{array}$ & 5 & 1 & 2 & 3 & 0 & 0 & 11 \\
$\begin{array}{l}\text { respiratório } \\
\text { Equilíbrio }\end{array}$ & 5 & 0 & 1 & 1 & 2 & 2 & 11 \\
Manutenção da & 11 & 5 & 5 & 4 & 6 & 3 & 34 \\
Postura & 6 & 6 & 9 & 12 & 9 & 10 & 52 \\
Orientação & 9 & 8 & 1 & 8 & 1 & 1 & 28 \\
Pós-Operatório & 1 & 1 & 2 & 1 & 0 & 2 & 7 \\
Transferência & 2 & 4 & 1 & 2 & 0 & 3 & 12 \\
Troca Postural & 6 & 5 & 10 & 3 & 9 & 8 & 41 \\
\hline
\end{tabular}

alguma particularidade que exigia uma avaliação mais específica. Ao definir a funcionalidade em diversos níveis e propondo extensas e detalhadas categorias a própria CIF nos permitiu adotar essa estratégia.

Em relação a aceitação da equipe, houve boa receptividade na apresentação do instrumento, porém pouca percepção sobre o real impacto do novo modelo na prática diária, tanto em relação a demanda de trabalho, quanto a aplicação em si.

A estratégia do piloto e de um novo treinamento quando a equipe já tinha experimentado o instrumento na prática foi essencial para o desenvolvimento e a adaptação dos terapeutas a seu uso, pois as dúvidas eram mais claras e consequentemente mais resolutivas.

\section{DISCUSSÃO}

A utilização dos qualificadores da CIF para avaliação da evolução do paciente durante seu segmento terapêutico já foi proposta no Brasil e no mundo, 2,26-28 porém sua aplicação de forma unificada entre os terapeutas de um grande centro de reabilitação é inovadora e se mostrou eficaz na prática para registro dos indicadores do setor institucionalmente.

Rauch $\mathrm{A}^{2}$ ao descrever como aplicar a CIF na prática clínica pontua a importância do uso dos qualificadores para quantificar a extensão da limitação nas funções trabalhadas com pacientes em reabilitação e propõe um modelo a ser seguido, porém não se aprofundam sobre a forma de realizar a qualificação de cada função. Como limitações cita o tempo consumido para realizar todas as etapas dos registros e a necessidade de sistemas que contenham formulários específicos para aplicação clínica. O nosso estudo se propõe a apresentar uma forma de trazer esse modelo de seguimento da reabilitação dos pacientes para a prática clínica dentro da área de fisioterapia.

É de se atentar que a literatura atual discute as propriedades psicométricas dos qualificadores genéricos da $\mathrm{CIF}$, pois quando testados em itens de funcionalidade para pacientes em reabilitação apresentaram confiabilidade inter-avaliador considerada de moderada a baixa na maioria dos itens avaliados. ${ }^{8,9}$ Estes estudos 
pontuam a importância do uso dos qualificadores e citam a necessidade de padronizar os testes realizados a fim de uma melhor confiabilidade.

O trabalho de Kohler $\mathrm{F}$ et al. ${ }^{29}$ por sua vez apresentou confiabilidade de moderada a boa na avaliação psicométrica do uso dos qualificadores, ao realizar pequenas adaptações nos qualificadores buscando simplificar a linguagem utilizada para o ponto de vista prático de aplicação dos terapeutas. Eles atribuem o maior sucesso na sua confiabilidade a essa adaptação realizada, que promoveu a equipe melhor entendimento de cada qualificador separadamente.

O presente estudo, percebendo a subjetividade apresentada pelos qualificadores genéricos na avaliação da funcionalidade do paciente também optou por realizar adaptações aos níveis apresentados padronizando-os em cada função. Para garantir sua consistência, apesar de bons resultados apresentados até o presente momento, o instrumento ainda deve passar pelo processo de validação.

Estudos que relacionaram os qualificadores da CIF com escalas validadas, apesar de não apresentarem análise de ordem psicométrica, variaram na forma de aplicação da escala. Garcia $M^{27}$ por exemplo, aplicaram testes de rotina em seus pacientes e somente após aplicação adaptaram a pontuação dos testes aos níveis funcionais apontados pela escala de qualificadore. Coelho $\mathrm{J}^{30}$ realizou um trabalho similar ao nosso grupo de adaptação dos qualificadores aos testes mais utilizados com a população de pacientes com sequelas de lesões medulares.

Nos trabalhos citados observou-se resultados satisfatórios para avaliar a condição funcional do paciente através dos qualificadores, mesmo cada autor realizando a adaptação de forma diferente. A limitação imposta pela classificação está sendo suprida por diferentes adaptações e deve ser continuada para aproximar uso da CIF da aplicação prática. ${ }^{31}$

Nesse estudo, além de sugerir uma padronização dos qualificadores propostos pela CIF para avaliação, obtivemos uma ferramenta que se mostrou capaz de detectar mudança na funcionalidade do paciente através da mudança do qualificador no período proposto, o que indica possibilidade de continuidade do uso e aprimoramento do instrumento para posterior validação em relação a sua sensibilidade.

Nosso instrumento utilizou diversas escalas para avaliar diferentes domínios, pois cada escala apresentava um ou alguns testes essenciais para avaliar a função em questão e que eram de fácil aplicação prática. Sendo a CIF tão completa e os códigos selecionados tão diversos, não encontramos uma única escala que avaliasse todas as funções desejadas.

Esse fato já foi comentado por Goljar N et al. ${ }^{7}$ e Prodinger B et al. ${ }^{32}$ que concordam que é um desafio integrar os qualificadores da CIF com escalas de medida fixa na prática clínica pois seus domínios abrangem mais do que os testes específicos.

As adaptações realizadas nos testes sempre visaram tornar o uso prático o mais fácil possível, mantendo os qualificadores objetivos para determinarem a evolução funcional dos nossos pacientes. Rentsch HP et al. ${ }^{33}$ relata sua experiência de utilização da CIF na em um centro de neuro-reabilitação na Suíça e cita que foi necessário adaptar o trabalho diversas vezes para reduzir o tamanho do instrumento de uma forma que o mantivesse adequado as necessidades do paciente e dos profissionais da instituição, o que se assemelha com a nossa experiência.

Quando se propõe novos modelos à uma equipe de trabalho, alguma resistência é esperada, porém percebemos que quando é proposto a participação ativa da equipe as mudanças são mais bem aceitas. Verhoef J et al. ${ }^{34}$ ao relatar a experiência de implantar a CIF numa equipe de reumatologia, destaca que resposta dos profissionais frente a novas propostas variam de acordo com o setor e a equipe, mas que ainda é muito importante a participação da equipe no processo para minimizar resistências. A experiência relatada na Suíça corrobora com esses achados e reforça a necessidade de envolver os profissionais no projeto antes da sua implementação.

Durante a introdução do novo modelo aqui exposto a resistência inicial dos terapeutas foi baixa e reduziu ao longo do semestre e chegando a representar somente $2 \%$ (relatórios com inconsistências no último mês). A boa adesão pode ser atribuída ao fato de o novo modelo representar os indicadores do setor e dos profissionais terem participado ao longo do processo de mudança, tanto na criação e melhora do instrumento.

Finalmente, apesar de todas as dificuldades, o ponto mais importante da implantação do novo modelo foi a possibilidade de representar a evolução funcional do paciente quantitativamente, fornecendo dados objetivos para os indicadores do serviço, uma linguagem simples para comunicação entre a equipe e com o paciente, possibilitando uma avaliação mais criteriosa por parte do terapeuta e a participação ativa do paciente no seu processo terapêutico. Consideramos válida e com boa aceitação a introdução do instrumento do setor.

Com essa iniciativa o centro de reabilitação pôde trazer uma classificação utilizada mundialmente para sua prática clínica, e, após constatado a viabilidade do processo, seu uso foi expandido para todos os setores para desenvolvimento de instrumentos seguindo os moldes desse projeto inicial. A longo prazo, acreditamos que este modelo permitirá traçar um perfil de evolução funcional, considerando a avaliação realizada na entrada do paciente na instituição, seu segmento terapêutico e sua condição no momento da alta.

Como limitações podemos citar que entendemos que ao realizar as adaptações apresentadas nos distanciamos dos testes validados em literatura, porém a mudança foi realizada de acordo com sugestões e comentários de profissionais muito experientes no assunto, para respeitar a nossa prática clínica, e se manter fiel ao que é proposto pelo conceito da CIF.

Literaturas apontam a necessidade de medir a confiabilidade de testes propostos para utilização prática da CIF. ${ }^{9}$ Reconhecemos essa necessidade e temos como projeto futuro desenvolver a validação das propriedades psicométricas do instrumento criado. A proposta desse trabalho foi somente relatar a experiência para que auxilie outros profissionais ou instituições que busquem levar a CIF para sua prática clínica.

Estamos cientes da existência dos Core Sets para a população com sequelas de LEA como o acidente vascular encefálico, ${ }^{35}$ o traumatismo crânio encefálico ${ }^{36}$ e outras condições de saúde que tratamos em nosso centro de reabilitação, porém optamos por não utiliza-los pois, como o novo instrumento já representou grande mudança na rotina dos profissionais do setor, preferimos manter os códigos mais conhecidos para facilitar a adaptação da equipe a nova proposta. Além disso por serem utilizados no setor de fisioterapia somente códigos específicos seriam avaliados e utilizando as classificações de até 3응 nível, mais detalhadas do que as utilizadas nos Core Sets.

Temos consciência que nos distanciamos um pouco do conceito amplificado da saúde ao não utilizar os códigos ambientais, porém o realizamos dessa forma também pensando na adaptação da equipe a nova proposta e por não termos definido como realizar sua tabulação até então. Sabemos que a proposta dos Core Sets não é para restringir a aplicação e que o uso da CIF é incentivado, mesmo que com adaptações para proximidade da prática, desde que possibilitem o uso de forma correta da classificação. ${ }^{37}$

\section{CONCLUSÃO}

A proposta de criação de uma ferramenta baseada na CIF e seus qualificadores para avaliação de pacientes para uso neste serviço de reabilitação foi iniciada com sucesso. A ferramenta mostrou-se capaz de acompanhar a evolução do paciente e auxiliar na programação de metas terapêuticas através de uma linguagem padronizada para a 
equipe. A melhoria da ferramenta com adição de códigos ambientais e a validação de suas propriedades psicométricas são necessárias para expansão da aplicação e guiarão nossos projetos futuros.

\section{REFERÊNCIAS}

1. CIF: Classificação Internacional de Funcionalidade, Incapacidade e Saúde. São Paulo: Edusp; 2003.

2. Rauch A, Cieza A, Stucki G. How to apply the International Classification of Functioning, Disability and Health (ICF) for rehabilitation management in clinical practice. Eur J Phys Rehabil Med. 2008;44(3):329-42.

3. World Confederation of Physical Therapy [homepage on the Internet] London: WCPT; c2019 [cited 2019 Aug 5].Available from: https://www.wcpt.org/

4. American Physical Therapy Association. APTA Endorses World Health Organization ICF model [text on the Internet]. Alexandria: APTA [cited 2008 June 06] Available from: https://www.apta.org/Media/Releases/APTA/2008/7/8/

5. Ruaro JA, Ruaro MB, Souza DE, Fréz AR, Guerra RO. An overview and profile of the ICF's use in Brazil--a decade of history. Rev Bras Fisioter. 2012;16(6):454-62.

6. Escorpizo R, Bemis-Dougherty A. Introduction to special issue: a review of the International Classification of Functioning, Disability and Health and physical therapy over the years. Physiother Res Int. 2015;20(4):200-9. DOI: https://doi.org/10.1002/pri.1578

7. Prodinger B, Stucki G, Coenen M, Tennant A. The measurement of functioning using the International Classification of Functioning, Disability and Health: comparing qualifier ratings with existing health status instruments. Disabil Rehabil. 2019;41(5):541-548. DOI: https://doi.org/10.1080/09638288.2017.1381186

8. Starrost K, Geyh S, Trautwein A, Grunow J, Ceballos-Baumann A, Prosiegel $\mathrm{M}$, et al. Interrater reliability of the extended ICF core set for stroke applied by physical therapists. Phys Ther. 2008;88(7):841-51. DOI: https://doi.org/10.2522/ptj.20070211

9. Grill E, Mansmann U, Cieza A, Stucki G. Assessing observer agreement when describing and classifying functioning with the International Classification of Functioning, Disability and Health. J Rehabil Med. 2007;39(1):71-6. DOI: https://doi.org/10.2340/16501977-0016

10. Cieza A, Brockow T, Ewert T, Amman E, Kollerits B, Chatterji S, et al. Linking health-status measurements to the international classification of functioning, disability and health. J Rehabil Med. 2002;34(5):205-10.

11. Cieza A, Geyh S, Chatterji S, Kostanjsek N, Ustün B, Stucki G. ICF linking rules: an update based on lessons learned. J Rehabil Med. 2005;37(4):212-8. https://doi.org/10.1080/16501970510040263

12. Riberto $M$, Miyazaki MH, Jucá SSH, Sakamoto $H$, Pinto PPN, Battistella LR. Validação da versão brasileira da Medida de Independência Funcional. Acta Fisiatr. 2004;11(2):72-6. DOI: https://doi.org/https://doi.org/10.5935/0104-7795.20040003

13. Miyamoto ST, Lombardi Junior I, Berg KO, Ramos LR, Natour J. Brazilian version of the Berg balance scale. Braz J Med Biol Res. 2004;37(9):1411-21.

https://doi.org/https://doi.org/10.1590/s0100$879 \times 2004000900017$

14. Shumway-Cook A, Brauer S, Woollacott M. Timed Up \& Go Test (TUG). Missouri Edu. 2000;80(1991):9-10.

15. Darzins SW, Imms C, Di Stefano M. Measurement of activity limitations and participation restrictions: examination of ICFlinked content and scale properties of the FIM and PC-PART instruments. Disabil Rehabil. 2017;39(10):1025-38. DOI: https://doi.org/10.3109/09638288.2016.1172670
16. Schepers VP, Ketelaar M, van de Port IG, Visser-Meily JM, Lindeman E. Comparing contents of functional outcome measures in stroke rehabilitation using the International Classification of Functioning, Disability and Health. Disabil Rehabil. 2007;29(3):221-30. https://doi.org/10.1080/09638280600756257

17. Horak FB, Wrisley DM, Frank J. The Balance Evaluation Systems Test (BESTest) to differentiate balance deficits. Phys Ther. 2009;89(5):484-98. DOI: https://doi.org/10.2522/ptj.20080071

18. Wanderley ELS, Teixeira-Salmela LF, Laurentino GE, Simões LC, Lemos A. Adaptação transcultural da Motor Assessment Scale (MAS) para o Brasil. Acta Fisiatr. 2015;22(2):65-71. DOI: https://doi.org/10.5935/0104-7795.20150014

19. Daniel CR, Battistella LR. Using the six minute walk test to evaluate walking capacity in patients with stroke. Acta Fisiatr. 2014;21(4):195-200. DOI: https://doi.org/10.5935/01047795.20140038

20. Castro SM, Perracini MR, Ganança FF. Versão brasileira do Dynamic Gait Index. Rev Bras Otorrinolaringol. 2006;72(6):81725. DOI: http://dx.doi.org/10.1590/S0034-72992006000600014

21. Hawker GA, Mian S, Kendzerska T, French M. Measures of adult pain: Visual Analog Scale for Pain (VAS Pain), Numeric Rating Scale for Pain (NRS Pain), McGill Pain Questionnaire (MPQ), Short-Form McGill Pain Questionnaire (SF-MPQ), Chronic Pain Grade Scale (CPGS), Short Form-36 Bodily Pain Scale (SF-36 BPS), and Measure of Intermittent and Constant Osteoarthritis Pain (ICOAP). Arthritis Care Res (Hoboken). 2011;63 Suppl 11:S240-52. DOI: https://doi.org/10.1002/acr.20543

22. Robertson JA. F. P. Kendall and E. K. McCreary "Muscles, Testing and Function" (Third Edition). Br J Sports Med. 1984;18(1):25.

23. Bohannon RW, Smith MB. Interrater reliability of a modified Ashworth scale of muscle spasticity. Phys Ther. 1987;67(2):206-7. DOI: https://doi.org/10.1093/ptj/67.2.206

24. Santos JDM, Oliveira MA, Silveira NJF, Carvalho SS, Oliveira AG. Confiabilidade inter e intraexaminadores nas mensurações angulares por fotogrametria digital e goniometria. Fisioter Mov. 2011;24(3):389-400. DOI: http://dx.doi.org/10.1590/S010351502011000300003

25. Coelho JN. A funcionalidade dos indivíduos com lesão medular de etiologia não-traumática: uma proposta para o uso da Classificação Internacional de Funcionalidade, Incapacidade e Saúde [Dissertação]. Ribeirão Preto: Universidade de São Paulo; 2015.

26. Li J, Prodinger B, Reinhardt JD, Stucki G. Towards the system-wide implementation of the International Classification of Functioning, Disability and Health in routine practice: lessons from a pilot study in China. J Rehabil Med. 2016;48(6):502-7. DOI: https://doi.org/10.2340/16501977-2067

27. Benito García M, Atín Arratibel MA, Terradillos Azpiroz ME. The Bobath concept in walking activity in chronic stroke measured through the International Classification of Functioning, Disability and Health. Physiother Res Int. 2015;20(4):242-50. DOI: https://doi.org/10.1002/pri.1614

28. Oliveira LR, Macedo APFS, Buchalla CM, Scatena JHG. Evolução da deficiência em vítimas de acidente de trânsito em reabilitação, caracterizada pela Classificação Internacional de Funcionalidade, Incapacidade e Saúde (CIF). Fisioter Mov. 2017;30(2):267-75. DOI: http://dx.doi.org/10.1590/1980-5918.030.002.ao07

29. Kohler F, Connolly C, Sakaria A, Stendara K, Buhagiar M, Mojaddidi $M$. Can the ICF be used as a rehabilitation outcome measure? A study looking at the inter- and intra-rater reliability of ICF categories derived from an ADL assessment tool. J Rehabil Med. 2013;45(9):881-7. DOI: https://doi.org/10.2340/16501977-1194 
30. Coelho JN, Almeida C, Vianna PC, Dalto VF, Castro FFS, Rabeh SAN, et al. Development of an ICF Core Set based instrument for individuals with non-traumatic spinal cord injury. Int J Phys Med Rehabil. 2017;5:432. DOI: https://doi.org/10.4172/23299096.1000432

31. Castaneda L, Castro SS. Publicaçoes brasileiras referentes à Classificaçao Internacional de Funcionalidade. Acta Fisiátr. 2013;20(1):29-36. DOI: https://doi.org/10.5935/0104 7795.20130006

32. Goljar N, Burger H, Vidmar G, Leonardi M, Marincek C. Measuring patterns of disability using the International Classification of Functioning, Disability and Health in the post-acute stroke rehabilitation setting. J Rehabil Med. 2011;43(7):590-601.DOI: https://doi.org/10.2340/16501977-0832

33. Rentsch HP, Bucher P, Dommen Nyffeler I, Wolf C, Hefti H, Fluri E, et al. The implementation of the 'International Classification of Functioning, Disability and Health' (ICF) in daily practice of neurorehabilitation: an interdisciplinary project at the Kantonsspital of Lucerne, Switzerland. Disabil Rehabil. $2003 \mathrm{Apr}$ 22;25(8):411-21.

DOI:
34. Verhoef J, Toussaint PJ, Putter H, Zwetsloot-Schonk JH, Vliet Vlieland TP. The impact of introducing an ICF-based rehabilitation tool on staff satisfaction with multidisciplinary team care in rheumatology: an exploratory study. Clin Rehabil. 2008;22(1):2337. DOI: https://doi.org/10.1177/0269215507079845

35. Geyh S, Cieza A, Schouten J, Dickson H, Frommelt P, Omar Z, et al. ICF Core Sets for stroke. J Rehabil Med. 2004;(44 Suppl):135-41. DOI: https://doi.org/10.1080/16501960410016776

36. Bernabeu M, Laxe S, Lopez R, Stucki G, Ward A, Barnes M, et al. Developing core sets for persons with traumatic brain injury based on the international classification of functioning, disability, and health. Neurorehabil Neural Repair. 2009 Jun;23(5):464-7. DOI: https://doi.org/10.1177/1545968308328725

37. Cieza A, Oberhauser C, Bickenbach J, Chatterji S, Stucki G. Towards a minimal generic set of domains of functioning and health. BMC Public Health. 2014;14:218. DOI: https://doi.org/10.1186/14712458-14-218

https://doi.org/10.1080/0963828031000069717

Anexo 1

\section{ANDAR e DESLOCAR-SE:}

d450 - Andar - Mover-se sobre uma superfície a pé, passo a passo, de maneira que um pé esteja sempre no solo, como passear, caminhar lentamente, andar para frente, para trás ou para o lado.

xxx.0 - Marcha comunitária independente: o paciente é capaz de deambular em todos os tipos de superfícies irregulares. Consegue percorrer uma distância considerável, até mesmo irrestrita.

xxx.1 - Deambula nas cercanias de casa ou na vizinhança: o paciente é capaz de deambular na rua, embora numa distância limitada e restrita.

xxx.2 - Marcha domiciliar: a deambulação só é possível em ambiente fechado, em superfícies planas e, geralmente, em um ambiente conhe cido e controlado, como em casa.

xxx.3 - Marcha terapêutica, não funcional. O paciente precisa ser apoiado firmemente por 1 ou 2 pessoas, e/ou a deambulação só é possível durante a terapia domiciliar ou no centro de reabilitação ou nas barras paralelas.

xxx.4 - Não realiza marcha; incapacidade absoluta para a deambulação, mesmo com auxílio externo.

d4500 - Andar distâncias curtas - Andar menos de $1 \mathrm{~km}$, como andar em quartos e corredores, dentro de um prédio ou distâncias curtas no exterior do prédio - avaliar independente do dispositivo auxiliar.

xxx.0 - Deambula acima de 400 metros em 6 minutos.

xxx.1 - Deambula de 200 a 400 metros em 6 minutos.

xxx.2 - Deambula de 100 a 200 metros em 6 minutos.

$x x x .3$ - Deambula de 10 a 100 metros em 6 minutos.

xxx.4 - Deambula no máximo 10 metros em 6 minutos.

d4502 - Andar sobre superfícies diferentes - Andar sobre superfícies inclinadas, irregulares ou móveis, como sobre grama, pedregulho, gelo ou neve, ou entrar em um navio trem ou outro veículo.

xxx.0 - Sobe e desce rampas andando ou de CR de forma independente sem uso de aditamentos ou corrimão.

xxx.1 - Sobe e desce rampas com uso de aditamentos, tocando CR em ambos os casos podendo ou não usar o corrimão sem supervisão.

$x x x .2$ - Sobe e desce rampas com uso de aditamentos, tocando CR podendo ou não usar o corrimão com supervisão.

xxx.3 - Sobe e desce rampas com uso de aditamentos e/ou corrimão com auxílio de terceiros ou suporte parcial para tocar CR.

xxx.4 - Não consegue subir e descer rampas e é conduzido na CR.

(Legenda: $C R=$ cadeira de rodas)

d4503 - Andar desviando de obstáculos - Andar de maneira necessária para evitar objetos moveis ou fixos, pessoas, animais e veículos, como andar em um supermercado ou loja, ao redor ou através do tráfego ou em espaços com muita gente - avaliar independente do dispositivo auxiliar.

d4503 - Ultrapassar Obstáculo:

Observação: Utilizar obstáculo funcional para o seu paciente - ex.: altura do obstáculo)

xxx.0 - Capaz de passar sobre obstáculo sem mudar a velocidade e com bom equilíbrio.

xxx.1 - Passa sobre obstáculo, mas reduz a velocidade, com bom equilíbrio.

xxx.2 - Passa sobre obstáculo com desequilíbrio ou toca.

xxx.3 - Reduz a velocidade com desequilíbrio, mas consegue realizar com assistência.

xxx.4 - Não consegue passar sobre o obstáculo.

OU

\section{d4503 - Contornar Obstáculo:}

Observação: Comece andando na sua velocidade normal e contorne os cones, um pela direita e outro pela esquerda (distância de $1,8 \mathrm{~m}$ entre eles).

xxx.0 - Normal: É capaz de contornar os cones com segurança, sem alteração da velocidade da marcha. Não há evidência de desequilíbrio.

xxx.1 - Comprometimento leve: É capaz de contornar ambos os cones, mas precisa diminuir o ritmo da marcha e ajustar os passos para não bater nos cones. Não há evidência de desequilíbrio.

xxx.2 - Comprometimento moderado: É capaz de contornar os cones sem bater neles, mas precisa diminuir significativamente a velocidade da marcha para realizar a tarefa, ou precisa de dicas verbais.

xxx.3 - Comprometimento grave: É capaz de contornar os cones, porém encosta neles ou precisa de auxílio (toque) de terceiros.

xxx.4 - É incapaz de contornar os cones; bate em um deles ou em ambos, ou precisa ser amparado.

d4600 - Deslocar-se dentro de casa (marcha domiciliar) - especificar o tipo de aditamento

$x x x .0$ - Desloca-se dentro e fora da casa (quintal) sem supervisão.

xxx.1 - Desloca-se dentro e fora da casa (quintal) com supervisão.

$x x x .2$ - Desloca-se por toda a casa com supervisão.

xxx.3 - Desloca-se entre dois cômodos com supervisão.

xxx.4 - Desloca-se dentro de um cômodo com supervisão. 
d4601 - Deslocar-se dentro de outros edifícios que não a própria casa (mercado, shopping- curtas distâncias)

$x x x .0$ - Desloca-se dentro de outros edifícios de forma independente, com ou sem aditamento ou CR.

xxx.1 - Desloca-se dentro de outros edifícios com ou sem aditamento ou CR e supervisão de terceiros.

xxx.2 - Desloca-se dentro de outros edifícios com ou sem aditamento ou CR e supervisão e auxílio de terceiros em poucos momentos.

xxx.3 - Desloca-se dentro de outros edifícios com ou sem aditamento ou CR e supervisão e auxílio de terceiros em muitos momentos.

xxx.4 - Desloca-se dentro de outros edifícios com aditamento ou CR e supervisão e auxílio de terceiros.

(Legenda: $C R$ = cadeira de rodas)

d4602 - Deslocar-se fora de casa e outros prédios - andar e deslocar-se perto ou longe da própria casa e de outros edifícios, sem a utilização de transporte, público ou privado, como por exemplo, andar distâncias pequenas e grandes numa aldeia ou cidade.

xxx.0 - Desloca-se em ambientes externos de forma independente, com ou sem aditamento ou $\mathrm{CR}$

xxx.1 - Desloca-se em ambientes externos com ou sem aditamento ou CR e supervisão de terceiros.

$x x x .2$ - Desloca-se em ambientes externos com ou sem aditamento ou CR e supervisão e auxílio de terceiros em poucos momentos.

xxx.3 - Desloca-se em ambientes externos com ou sem aditamento ou CR e supervisão e auxílio de terceiros em muitos momentos.

xxx.4 - Não consegue deslocar-se em ambientes externos.

(Legenda: $C R$ = cadeira de rodas)

d4551 - Subir/descer - Mover todo o corpo para cima ou para baixo sobre superfícies ou objetos, como subir degraus, rochas, escadas moveis ou fixas, meio-fio ou outros objetos. d4551 - Escadas:

xxx.0 - Normal: Alterna os pés, não usa o corrimão

xxx.1 - Comprometimento leve: Alterna os pés, mas precisa usar o corrimão.

xxx.2 - Comprometimento moderado: Coloca os dois pés em cada degrau; precisa usar o corrimão.

xxx.3 - Comprometimento grave: Coloca os dois pés em cada degrau; utiliza mais força no apoio do corrimão ou precisa de ajuda de terceiros (levantar a perna, do lado oposto do corrimão).

xxx.4 - Não consegue realizar a tarefa com segurança.

OU

\section{d4551 - Degrau/guia:}

$x x x .0$ - Sobe um degrau ou guia de rua de forma independente e sem dispositivo auxiliar

$x x x .1$ - Sobe um degrau ou guia de rua de forma independente e com dispositivo auxiliar.

$x x x .2$ - Sobe um degrau ou guia de rua com dispositivo auxiliar e ajuda de terceiros.

$x x x .3$ - Sobe um degrau ou guia de rua com dispositivo auxiliar e grande esforço por parte de terceiros.

xxx.4 - Não consegue subir um degrau ou guia de rua.

b770 - Funções relacionadas ao padrão de marcha - Funções relacionadas aos padrões de movimento como andar, correr ou outros movimentos do corpo inteiro.

Inclui: padrões de andar e correr; deficiência como marcha espástica, marcha paraplégica, marcha hemiplégica, marcha assimétrica, claudicação e padrão de marcha rígida.

Exclui: funções relacionadas à força muscular, funções relacionadas ao tônus muscular, funções relacionadas ao controle de movimentos voluntários, funções relacionadas aos movimentos involuntários.

Fases da Marcha:

Fase de apoio: contato inicial resposta a carga, apoio médio, apoio terminal, desprendimento ou pré-balanço.

Fase de balanço: balanço inicial, balanço médio e balanço final.

Possíveis alterações:

Pé/Tornozelo: Pronação do pé, Supinação do pé, Flexão plantar de rebote ou exagerada, Impulsão insuficiente, Choque do pé no solo.

Joelho: Hiperextensão de joelho, Flexão excessiva do joelho.

Quadril: Flexão inadequada de quadril, Extensão inadequada de quadril. Pelve: Queda da pelve, Elevação da Pelve.

Tronco: Flexão lateral excessiva do tronco, Flexão anterior excessiva do tronco, Rotação excessiva do tronco.

xxx.0 - Marcha sem alterações biomecânicas ou discretos desvios fisiológicos.

xxx.1 - Marcha com leve desvio biomecânico do segmento - paciente consegue controlar quando solicitado ou quando percebe.

xxx.2 - Marcha com moderado desvio biomecânico do segmento - realiza compensações durante a marcha.

xxx.3 - Marcha com grave desvio biomecânico do segmento - realiza importante compensações durante a marcha.

xxx.4 - Desvio biomecânico que impossibilita descarga de peso ou desprendimento no Ml afetado.

(Legenda: $M I=$ membro inferior)

\section{PARA MARCHA COM ADITAMENTOS:}

d465 - Deslocar-se usando algum tipo de equipamento (marcha com aditamento) - mover todo o corpo de um lugar para outro sobre qualquer superfície ou espaço utilizando dispositivos específicos para facilitar a movimentação ou criar outras maneiras de se mover com equipamentos como patins, esquis, equipamento de mergulho, ou deslocar-se na rua com cadeira de rodas ou andador.

xxx.0 - Nenhum aditamento, podendo utilizar de dispositivos como tira de Stuss, estabilizador de tornozelo, estribo para garra e outros de auxílio simples.

xxx.1 - Bengala de 1 ponto ou bastão de caminhada, com ou sem AFOs no geral que o paciente é capaz de colocar de forma independente.

xxx.2 - Muleta canadense ou axilar unilateral ou bengala de 4 pontos com ou sem AFOs no geral que o paciente não é capaz de colocar de forma independente.

xxx.3 - Muletas axilares ou canadenses bilaterais.

xxx.4 - Andador.

(Legenda: AFOs $=$ Ankle Foot Orthesis)

ou

\section{PARA DESLOCAMENTO NA CR}

d465 - Deslocar-se usando algum tipo de equipamento - mover todo o corpo de um lugar para outro sobre qualquer superfície ou espaço utilizando dispositivos específicos para facilitar a movimentação ou criar outras maneiras de se mover com equipamentos como patins, esquis, equipamento de mergulho, ou deslocar-se na rua com cadeira de rodas ou andador.

xxx.0 - Independente no uso de cadeira de rodas. Faz as manobras necessárias para se deslocar e propulsiona a cadeira por pelo menos 50 metros

xxx.1 - Propulsiona em terrenos irregulares. Assistência mínima em subir e descer degraus, guias.

xxx.2 - Assistência para manipular a cadeira para a mesa, cama, banheiro.

xxx.3 - Propulsiona a cadeira por curtas distâncias, superfícies planas. Assistência em todo o manejo da cadeira.

xxx.4 - Dependente na ambulação em cadeira de rodas.

d220 - Realizar tarefas múltiplas - realizar ações simples ou complexas e coordenadas como componentes de realizar tarefas múltiplas, integradas e complexas em sequência ou simultaneamente.

Timed up and Go com dupla tarefa (tempo em segundos)

Sugestões: para afásicos utilizar perguntas que o terapeuta faz enquanto o paciente faz o teste - para ele pensar, mesmo que não responda-, ou tentar cantar uma música.

xxx.0 - Normal: Nenhuma mudança notável entre sentado e de pé, no ritmo ou precisão da contagem regressiva e nenhuma mudança na velocidade da marcha.

xxx.1 - Leve: Desaceleração notável, hesitação ou erros na contagem regressiva OU marcha lenta (em 10\%) na dupla tarefa.

xxx.2 - Moderado: Afeta AMBAS as tarefas - afeta a tarefa cognitiva E diminui a velocidade de marcha (em $\leq 10 \%)$ na dupla tarefa.

xxx.3 - Grave: Afeta AMBAS as tarefas - afeta a tarefa cognitiva E diminui a velocidade de marcha (em > 10\%) na dupla tarefa.

xxx.4 - Não consegue contar regressivamente enquanto anda ou para de andar enquanto fala.

\section{TRANSFERÊNCIAS:}


xxx.1 - Transfere para superfícies mais altas com auxílio.

$x x x .2$ - Transfere para superfícies mais baixas sem auxílio

xxx.3 - Auxilia na transferência.

xxx.4 - Inicia a transferência com auxílio total.

d4208 - Transferir-se a própria posição, outra especificada - Mover-se de uma superfície para outra, como escorregar em um banco ou mover-se da cama para cadeira, sem mudar a posição do corpo. Deslocar-se enquanto estiver sentado ou deitado.

xxx.0 - A pessoa de aproxima da cama ou da cadeira, aciona o freio, ajusta os pedais e remove o apoio dos braços caso necessário; transfere-se (ficando em pé ou deslizando) e retorna. Executa com segurança. Requer dispositivos de ajuda ou adaptação (prótese ou órtese) tais como equipamentos móveis ou de elevação, bancos ou cadeiras especiais, suportes ou muletas. Leva em tempo acima do razoável ou existem riscos de segurança.

xxx.1 - Requer supervisão (alguém ao lado, incentivo, sugestão) ou preparação (posicionando os equipamentos moveis, ajustando os peda is, etc) ou quando é preciso apenas tocar o paciente em auxílio para a realização das tarefas, o paciente executa $75 \%$ ou mais das tarefas.

xxx.2 - Assistência moderada - a pessoa executa 50 a $74 \%$ das tarefas - trava a cadeira, retira o pé do apoio e afasta o apoio, remove o apoio do braço, leva o quadril para a beira da cadeira, posiciona o braço na outra superfície, precisa de alguém para elevar o paciente e rodar seu quadril - segura por cima do ombro. Terceiros afastam a CR ao final do movimento. xxx.3 - Assistência máxima - a pessoa executa 25 a $49 \%$ das tarefas - paciente pode preparar o ambiente, porém precisa ser lembrada dos passos ou não realiza tudo de forma independente. Precisa ser auxiliada por baixo dos braços com grande força de terceiros, auxilia fazendo força nos MMII (não suficiente para levantar-se sozinho) e girando os pés xxx.4 - Assistência total - a pessoa executa menos de $25 \%$ das tarefas - terceira pessoa prepara o ambiente, eleva paciente e executa o giro sem auxílio do paciente.

(Legenda: $M M I I=$ membros inferiores)

\section{TROCAS POSTURAIS:}

d4100 - Deitar-se - Adotar e abandonar a posição deitada ou mudar a posição horizontal do corpo de qualquer outra posição, como levantar-se ou sentar-se.

xxx.0 - Passa para deitado com agilidade e controle.

$x x x .1$ - Passa para deitado sem apoio.

xxx.2 - Assume até 45 e necessita de auxílio para finalizar a passagem.

xxx.3 - Inicia a passagem, mas ainda necessita de auxílio.

$x x x .4$ - Tem intenção de iniciar a passagem.

d4102 - Ajoelhar-se - adotar e abandonar a posição em que o corpo está apoiado nos joelhos com as pernas dobradas, como por exemplo, quando se reza, ou mudar a posição do corpo de ajoelhado para qualquer outra posição, como por exemplo, levantar-se.

xxx.0 - Passa para ajoelhado sem apoio e mantêm tronco alinhado.

xxx.1 - Passa para ajoelhado sem apoio, mas mantêm tronco discretamente anteriorizado.

$x x x .2$ - Passa para ajoelhado com apoio.

$x x x .3$ - Necessita de auxílio para assumir a postura ajoelhada, mas permanece com o tronco anteriorizado.

xxx.4 - Não adota a postura ajoelhada.

4107 - Rolar - Mover o corpo deitado de uma posição para outra, de um lado para ou outro ou mudar a posição de deitado de costas para de barriga para baixo.

xxx.0 - Rola para o lado em 3 segundos sem a utilização das mãos. Independente.

xxx.1 - Movimenta o braço ativamente cruzando o corpo, a perna é movida ativamente e o restante do corpo segue em bloco. Independente com compensação ou supervisão.

xxx.2 - O braço é levado cruzando o corpo junto com o outro braço. A perna é movida ativamente, porém é necessário toque leve para que o corpo acompanhe em bloco ou paciente usa as bordas da cama para tracionar-se.

xxx.3 - Movimenta a perna ativamente cruzando o corpo, braço é deixado para trás (só é levado quando lembrado ou com auxílio), não há movimento das cinturas pélvicas e escapulares

a não ser que exista toque moderado direcionando uma delas ou as duas.

xxx.4 - Paciente não realiza a tarefa - cuidador leva (faz toda a força) para girar ambas as cinturas e posicionar MMII e MMSS em decúbito lateral estabilizando paciente na posição.

(Legenda: $\mathrm{MMII}=$ membros inferiores; $\mathrm{MMSS}=$ membros superiores)

d4103 - Sentar-se - adotar e abandonar uma posição sentada ou mudar a posição do corpo de sentado para qualquer outra posição, como levantar-se ou deitar-se.

xxx.0 - Supino para sentado na lateral da cama. (Sem auxílio)

xxx.1 - Decúbito lateral para sentado na lateral da cama. (Com supervisão).

xxx.2 - Decúbito lateral para sentado na lateral da cama. (Avaliador dá auxílio, assistindo as pernas do paciente na lateral da cama).

xxx.3 - Decúbito lateral para sentado na lateral da cama. (Avaliador auxilia o paciente com movimento. Paciente controla a posição da cabeça durante o tempo todo).

xxx.4 - Deitado de lado, levanta a cabeça, mas não se senta. (É auxiliado para permanecer em decúbito lateral).

d4104 - Levantar-se - adotar e abandonar uma posição de estar em pé ou mudar a posição do corpo de estar em pé para qualquer outra posição, como de itar-se ou sentar-se.

xxx.0 - Levanta-se, sem apoio/aditamentos.

xxx.1 - Levanta-se com apoio/aditamentos.

$x x x .2$ - Inicia a passagem, mas necessita do auxílio de terceiros para completar a troca postural.

$x x x .3$ - Tem intenção de iniciar a passagem, mas necessita do auxílio de terceiros, para realizar a troca postural.

xxx.4 - Não inicia a passagem.

d4105 - Inclinar-se - inclinar as costas para baixo ou para o lado, como ao fazer uma reverência ou abaixar-se para pegar um objeto

Alcance funcional para frente

xxx.0 - Máximo para os limites: $>32 \mathrm{~cm}$

xxx.1 - Moderado: $24 \mathrm{~cm}-32 \mathrm{~cm}$

$x x x .2$ - Pobre: $16,5 \mathrm{~cm}-24 \mathrm{~cm}$.

$x x x .3$ - Muito pobre: $<16,5 \mathrm{~cm}$.

xxx.4 - Inclinação não mensurável.

OU

Alcance funcional latera

xxx.0 - Máximo para o limite: $>25,5 \mathrm{~cm}$

xxx.1 - Moderado: $17-25,5 \mathrm{~cm}$.

xxx.2 - Pobre: $10-17 \mathrm{~cm}$.

$x x x .3$ - Muito pobre: $<10 \mathrm{~cm}$.

xxx.4 - Inclinação não mensurável.

\section{MANUTENÇÃO DA POSTURA:}

d4155 - Manter posição da cabeça - Controlar a posição da cabeça e sustentar seu peso por um determinado período de tempo.

xxx.0 - Manter controle cervical e realiza movimentos com controle.

xxx.1 - Manter extensão cervical na postura sentada, por 30 segundos ou mais.

xxx.2 - Manter extensão cervical na postura sentada, por menos de 30 segundos.

xxx.3 - Inicia a extensão cervical na postura sentada.

xxx.4 - Não realiza a extensão cervical na postura sentada.

d4153 - Permanecer sentado - Permanecer sentado, em uma cadeira ou no chão, pelo tempo necessário, como quando sentado em uma carteira ou mesa. Permanecer sentado com pernas retas ou cruzadas, com pés apoiados ou sem apoio.

xxx.0 - Senta em um banquinho sem suporte, alcança os dois lados para tocar o chão e volta à posição inicial.

xxx.1 - Senta sem suporte, vira a cabeça e o tronco para olhar para trás. (Pés juntos e apoiados no chão. Não permitir abdução dos membros inferiores ou movimentação dos pés. Mãos descansam sobre as coxas).

xxx.2 - Senta sem suporte jogando peso anteriormente e bem distribuído, sem desequilíbrios internos. (Peso deve estar à frente dos quadris, cabeça e coluna torácica estendidos, peso igualmente distribuído em ambos os hemicorpos).

xxx.3 - Senta sem suporte por 10 segundos apenas (Sem se segurar, os joelhos unidos e os pés apoiados no chão) ou por maior tempo sendo necessário apoio do MS no assento para manutenção da postura. 
xxx.4 - Senta-se somente com suporte (avaliador deve assistir o paciente)

d4154 - Permanecer em pé - Permanecer em pé durante o tempo necessário, como quando se espera em uma fila. Permanecer de pé em superfícies inclinadas, escorregadias ou duras.

xxx.0 - Permanece em pé com as mãos livres para função.

xxx.1 - Permanece em pé com apoio de uma das mãos.

xxx.2 - Permanece em pé com apoio das duas mãos ou uma com supervisão.

xxx.3 - Permanece em pé com suporte externo (prancha ortostática, tala extensora, stand-in-table, parapodium).

xxx.4 - Não consegue ficar em pé.

\section{EQUILÍBRIO:}

b2351 - Funções relacionadas aos reflexos de movimentos involuntários - Funções de contrações involuntárias de grandes músculos, ou de todo o corpo induzidas pela posição do corpo, equilíbrio e estímulos ameaçadores. Funções de reações posturais, reação de endireitar o corpo, reações de adaptação do corpo, reações de equilíbrio, reações de apoio, reações de defesa.

Sugestões: Realizar os testes de acordo com o objetivo do seu paciente - os testes podem variar utilizando base fechada ou aberta, olhos abertos ou fechados, superfície estável ou instável, rampa ou não, ou uma combinação deles. Descreva como está sendo realizado e pontue de acordo com a escala:

b2351 - ESTÁTICO

xxx.0 - Mantem de forma segura, pés próximos, sem apoio dos MMSS por tempo $>30$ segundos.

xxx.1 - Mantem de forma instável ou com base aumentada sem apoio dos MMSS por tempo $<30$ segundos.

xxx.2 - Mantem com apoio de MMSS por tempo > 30 segundos.

xxx.3 - Mantem com apoio de MMSS por tempo < 30 segundos.

xxx.4 - Não é capaz de ficar na posição escolhida.

(Legenda: MMSS = membros superiores)

OU

\section{b2351 - DINÂMICO}

Marcha com movimentos horizontais (rotação) da cabeça:

xxx.0 - Durante a marcha realiza as rotações da cabeça suavemente, sem alteração.

xxx.1 - Realiza as rotações da cabeça suavemente, com leve alteração da velocidade da marcha, ou seja, com mínima alteração da progressão da marcha.

xxx.2 - Durante a marcha realiza rotações da cabeça com moderada alteração da velocidade, diminui a velocidade, ou cambaleia, mas se recupera e consegue continuar a andar.

xxx.3 - Marcha sem rotação da cabeça, com velocidade reduzida ou cambaleia, mas se recupera e consegue continuar a andar.

xxx.4 - Marcha sem rotação de cabeça, com grave distúrbio da marcha, ou seja, cambaleando para fora do trajeto, perde o equilíbrio, para procura apoio na parede, ou precisa ser amparado mesmo com uso de aditamento.

d4106 - Mudar o centro de gravidade do corpo - mudar ou mover o peso do corpo de uma posição para outra enquanto sentado, de pé ou deitado, como por exemplo, mudar o apoio de um pé para o outro enquanto de pé - Alinhamento do centro de massa (caso use meio auxiliar pontuar uma categoria abaixo)

xxx.0 - Alinhamento normal AP e ML do CM e alinhamento postural segmentar normal.

xxx.1 - Alinhamento anormal AP ou ML do CM OU alinhamento postural anormal.

$x x x .2$ - Alinhamento anormal AP ou ML do CM E alinhamento postural anormal.

xxx.3 - Alinhamento normal AP e ML do CM com apoio de MMSS.

xxx.4 - Alinhamento anormal AP e ML do CM mesmo com apoio de MMSS

(Legenda: $A P=$ anteroposterior; $M L=$ médio-lateral; $C M=$ centro de massa; $M M S S=$ membros superiores)

\section{ORIENTAÇÕES:}

d198 - Aprendizagem e aplicação de conhecimento, outros especificados -

Dividir as orientações dadas em porcentagens para pontuação adequada de compreensão e adesão.

xxx.0 - Compreende, reproduz corretamente e relata realizar todas as orientações dadas em casa.

xxx.1 - Compreende, reproduz e relata dificuldade LIGEIRA para realizar todas as orientações dadas em casa (leve, pequeno, ...) 5-24\%

xxx.2 - Compreende, reproduz e relata dificuldade MODERADA realizar todas as orientações dadas em casa (médio, regular, ...) 25-49\%

xxx.3 - Compreende, reproduz e relata dificuldade GRAVE para realizar todas as orientações dadas em casa (grande, extremo, ...) 50-95\%

xxx.4 - Relata dificuldade COMPLETA para compreender e reproduzir em casa todas as orientações dadas (total, ....) 96-100\%

\section{CONDICIONAMENTO/ FUNÇÕES RESPIRATÓRIAS:}

b455 - Funções de tolerância a exercícios (resistência física geral, capacidade aeróbia, fadiga, tolerância a exercícios) - funções relacionadas a capacidade respiratória e cardiovascular necessária para suportar exercícios físicos. Funções de resistência física, capacidade aeróbia, vigor e fadiga - Cansaço referido na escala de Borg antes e após teste escolhido (Teste de Caminhada de 6 minutos, por exemplo), relatando teste utilizado. Escolher se uso para resistência muscular ou cardiopulmonar.

xxx.0 - Pontuação de 0 ou 1 na escala de Borg.

xxx.1 - Pontuação de 2 a 4 na escala de Borg.

$x x x .2$ - Pontuação de 5 ou 6 na escala de Borg.

xxx.3 - Pontuação de 7 ou 8 na escala de Borg.

xxx.4 - Pontuação 9 ou 10 na escala de Borg.

\section{PO - PÓS-OPERATÓRIO:}

b280 - Sensação de Dor - sensação desagradável que indica lesão potencial ou real em alguma estrutura do corpo. Sensação de dor generalizada ou localizada, em uma ou mais partes do corpo, dor em um dermátomo, aguda, em queimação, imprecisa, continua e localizada: deficiências como mialgia, analgesia e hiperalgesia.

$x x x .0-E V A=0-1$ (nenhuma, ausente, insignificante)

$x x x .1-E V A=2-4$ (dor leve)

$x x x .2-E V A=5-6$ (dor moderada)

$x x x .3-E V A=7-8$ (dor grave)

$x x x .4-E V A=9-10$ (dor insuportável)

(Legenda EVA= Escala Visual Analógica)

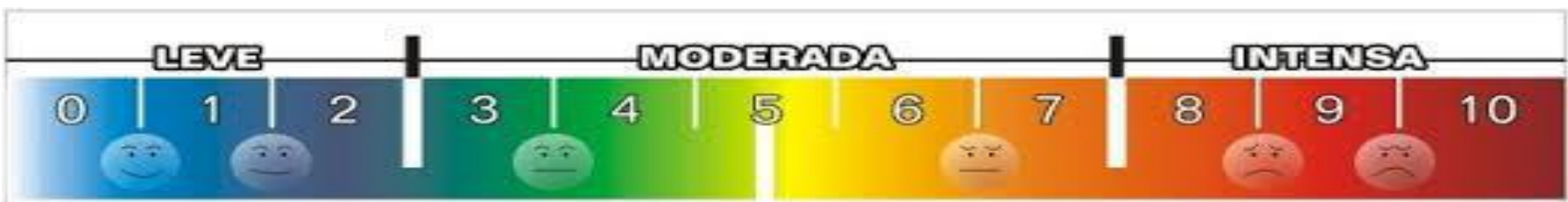

b4352 - Funções dos vasos linfáticos - funções relacionadas com os canais vasculares que transportam linfa.

xxx.0 - Ausência de edema OU edema discreto quando permanece com MMII baixos durante grandes períodos de tempo ou ao final do dia.

xxx.1 - Edema leve 1+/4+ constante ou moderado quando permanece com MMII baixos durante grandes períodos de tempo ou ao final do dia.

$x x x .2$ - Edema moderado $2+/ 4+$ constante.

xxx.3 - Edema grave $3+/ 4+$ constante.

xxx.4 - Edema completo $4+/ 4+$ 
b820 - Funções reparadoras da pele (cicatrização, aderências) - funções da pele para a reparação de soluções de continuidade, ferimentos e de outros danos na pele. Funções da formação de crostas, cicatrização; contusão e formação de queloides.

xxx.0 - Ausência de aderências.

xxx.1 - Aderência leve $1+/ 4+-$ existe fibrose que não afeta mobilidade da pele ou segmentos.

xxx.2 - Aderência moderada 2+/4+ - fibrose que afeta a mobilidade da pele em volta, porém não afeta mobilidade de segmentos.

xxx.3 - Aderência grave 3+/4+ - fibrose importante que afeta a mobilidade da pele e tecidos adjuntos, podendo atrapalhar a mobilidade de segmentos (especialmente por dor).

xxx.4 - Aderência completa 4+/4+ - fibrose que afeta mobilidade dos tecidos adjuntos e impede mobilidade de segmento.

b710 - Funções relacionadas à mobilidade das articulações - funções relacionadas com a amplitude e a facilidade de movimento de uma articulação. Funções relacionadas à mobilidade de uma ou várias articulações, coluna vertebral, ombro, cotovelo, cintura, quadril, joelho, tornozelo, pequenas articulações das mãos e pés; mobilida de generalizada das articulações; deficiências como hipermobilidade das articulações, rigidez articular, ombro congelado, artrite.

xxx.0 - Ganhou $100 \%$ da amplitude inicial (de $20^{\circ}$ ele reduziu $20^{\circ}$ )

xxx.1 - Ganhou 50\% da amplitude inicial.

xxx.2 - Melhora de $20 \%$ da amplitude inicial.

xxx.3 - Melhora de $10 \%$ da amplitude inicial.

xxx.4 - Manteve a amplitude inicial.

b730 - Funções relacionadas à força muscular - funções relacionadas com a força gerada pela contração de um músculo ou de grupos de músculos. Funções associadas com a força de músculos específicos e grupos musculares, músculos de um membro, de um lado do corpo, da parte inferior do corpo, de todos os membros, do peito e do corpo como um todo; deficiências como fraqueza dos pequenos músculos dos pés e das mãos, paresia muscular, paralisia muscular, monoplegia, hemiplegia, paraplegia, tetraplegia e mutismo acinético.

xxx.0 - Grau 5, normal, consegue realizar movimento superando grandes resistências.

xxx.1 - Grau 4, bom, consegue realizar o movimento vencendo a gravidade e também alguma força externa.

xxx.2 - Grau 3, regular, consegue realizar movimento vencendo a gravidade.

xxx.3 - Grau 2, fraco, há movimento somente na ausência de gravidade.

xxx.4 - Grau 0, nula, ausência de contração ou grau 1, esboço, leve contração porem incapaz de produzir movimento.

b735 - Funções relacionadas ao tônus muscular - funções relacionadas com a tensão presente nos músculos em repouso e a resistência oferecida quando se tenta mover os músculos passivamente. Funções associadas à tensão de músculos isolados e grupos musculares, músculos de um membro, de um lado do corpo e da metade inferior do corpo músculos de todos os membros, músculos do tronco, e todos os músculos do corpo; deficiências, tais como, hipotonia, hipertonia e espasticidade muscular, miotomia e paramiotonia.

xxx.0 - Nenhum aumento no tônus muscular.

xxx.1 - Leve aumento no tônus muscular, manifestado por uma tensão momentânea ou por resistência mínima no final da amplitude de movimento articular, quando a região é movida em flexão ou extensão; 1+: leve aumento no tônus muscular, manifestado por tensão abrupta, seguida de resistência mínima em menos da metade da ADM restante.

xxx.2 - Aumento mais marcante do tônus muscular, durante a maior parte da ADM, mas a região é movida facilmente.

xxx.3 - Considerável aumento no tônus muscular, o movimento passivo é difícil.

xxx.4 - Parte afetada rígida em flexão ou extensão.

(Legenda: $A D M=$ amplitude de movimento)

b720 - Funções relacionadas a resistência muscular - funções relacionadas com a sustentação da contração muscular pelo período de tempo necessário. Funções associadas à sustentação da contração de músculos isolados, de grupos musculares, e de todos os músculos do corpo; deficiências como miastenia gravis.

Sugestão: Manobras deficitárias: Mingazinni (quadris, joelhos e tornozelos a 90\%), Barret (MMSS estendidos com ombros a 90ㅇ de flexão) ou outra posição especificada que baseie o objetivo (utilizar qualquer que seja a posição desejada ou grupo muscular observado e tomar a base dos 2 minutos)

xxx.0 - Mantem por 2 minutos sem queda em nenhum segmento.

xxx.1 - Mantem por 2 minutos com desalinhamento em algum segmento.

xxx.2 - Mantem de 1 minuto a 1 minuto e 59 segundos sem queda em nenhum segmento.

xxx.3 - Mantem de 1 minuto a 1 minuto e 59 segundos com desalinhamento em algum segmento.

xxx.4 - Não mantém a posição por 1 minuto.

(Legenda: MMSS = membros superiores)

\section{AVD'S (Atividades de Vida Diária):}

d540 - Vestir-se - realizar as tarefas e os gestos coordenados necessários para pôr e tirar a roupa e o calçado, segundo uma sequência adequada. e de acordo com as condições climáticas e sociais, como por exemplo, vestir, compor e tirar camisas, saias, blusas, calças, roupa interior, saris, quimonos, meias, casacos, calçar sapatos, botas, sandálias e chinelos, por luvas e chapéus Inclui: pôr ou tirar roupas e calçado e escolher as roupas apropriadas.

xxx.0 - Independência Completa - vestir-se e despir-se, buscando obter as roupas de armários e gavetas, manejando agasalhos ou camisas abertas ou fechadas, soutiens, zíperes e botões; coloca e remove próteses ou órteses. Desempenho seguro. Independência Modificada - exige adaptações (como o velcro ou dispositivo de ajuda), ou assistência (incluindo prótese e órtese) ou quando leva um tempo acima do razoável.

xxx.1 - Supervisão ou Preparação - exige supervisão (estar alguém ao lado, incentivo, sugestão) ou preparação (aplicação de órtese ou de equipamento especializa do). Assistência com Contato Mínimo - quando é preciso apenas tocar o paciente em auxílio para a realização das tarefas, o paciente executa $75 \%$ ou mais das tarefas.

xxx.2 - Assistência Moderada - a pessoa executa 50 a $74 \%$ das tarefas.

xxx.3 - Assistência Máxima - a pessoa executa 25 a $49 \%$ das tarefas.

xxx.4 - Assistência Total - a pessoa executa menos de $25 \%$ das tarefas.

d550 - Comer - executar as tarefas e os gestos coordenados necessários para ingerir os alimentos servidos, levá-los à boca e consumi-los de maneira culturalmente aceitável, cortar ou partir os alimentos em pedaços, abrir garrafas e latas, utilizar os talheres; participar em refeições, banquetes e jantares.

xxx.0 - Independência Completa - come de um prato, bebe de uma xícara ou copo, sabendo tratar diferentes tipos de comida e com a refeição disposta na forma clássica sobre uma mesa ou bandeja. O paciente usa colher ou garfo para levar a comida à boca; a comida é mastigada e engolida. Independência Modificada - necessita de um dispositivo de adaptação ou apoio, tal como canudo longo, espeto, faca rotativa; despende, para comer, um tempo acima do razoável, necessita alterar a consistência da comida ou liquefazê-la ou exige cuidados de segurança no ato de comer. Se a pessoa usa outras formas de alimentação (parental ou gastronomia) ela é capaz de fazê-lo por si própria.

xxx.1- Supervisão ou Preparação - necessita de supervisão (por exemplo, alguém ao lado, incentivo, sugestão) ou preparação (aplicação de órtese); ou quando é p reciso a ajuda de alguém para abrir as embalagens, cortar carne, passar manteiga no pão ou despejar líquidos, sem contato físico. Assistência com Contato Mínimo - quando é preciso apenas tocar o paciente em auxílio para a realização das tarefas, o paciente executa $75 \%$ ou mais das tarefas de alimentação.

xxx.2 - Assistência Moderada - a pessoa executa 50 a $74 \%$ das tarefas de alimentação.

xxx.3 - Assistência Máxima - a pessoa executa 25 a $49 \%$ das tarefas de alimentação.

xxx.4 - Assistência Total - a pessoa executa menos de $25 \%$ das tarefas. Ou, quando sua alimentação se faz em parte por via oral e em parte por outras

vias (parental ou gastronomia), e ela não consegue administrá-las por si própria. 